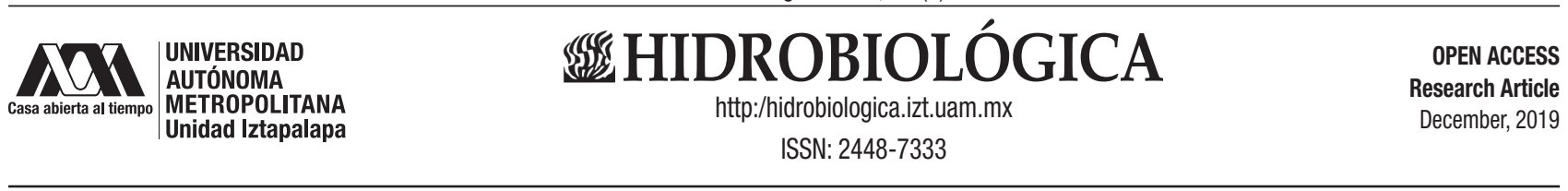

\title{
Allometric growth and reduced pectoral fin regeneration rate in terrestrialized Polypterus senegalus
}

\author{
Crecimiento alométrico y disminución de la capacidad de regeneración de la aleta pectoral en Polypterus senegalus terrestrizados
}

\author{
Rodrigo Cuervo-González ${ }^{1 *}$, Pablo San Martín del Angel ${ }^{1}$ and Luis Covarrubias ${ }^{2}$
}

Facultad de Ciencias Biológicas y Agropecuarias, Universidad Veracruzana, Tuxpan, Veracruz, 92850. México

2 Department of Developmental Genetics and Molecular Physiology, Instituto de Biotecnología, Universidad Nacional Autónoma de México.Avenida Universidad 2001 Colonia Chamilpa, Cuernavaca, Morelos, 62210. México

*Corresponding author:

Rodrigo Cuervo-González: e-mail: rodcuervo@uv.mx

To quote as:

Cuervo-González R., P. San Martín del Ange \& L. Covarrubias. 2019. Allometric growth and reduced pectoral fin regeneration rate in terrestrialized Polypterus senegalus. Hidrobiológica 29 (3): 155-161.

DOl: 10.24275/uam/iz/dcbs/hidro/2020v29n3/ Cuervo

\section{ABSTRACT}

Background: Polypterus condense unique characteristics that astonished and confused naturalists since 1802 when Geoffroy St. Hilaire first described and named this fish. Polypterus was seen in that epoch as primitive amphibians or a link between fishes and amphibians. Polypteriformes have the ability to regenerate its pectoral fins with the accuracy only seen in urodel amphibians and have the capacity to breathe air using paired lungs. Goals: We aimed to evaluate how forced land-living condition (i.e., terrestrialization) could affect pectoral girdle bones shape and pectoral fin regeneration in Polypterus senegalus. Methods: Polypterus were reared in semi-terrestrial conditions for nine months and iterative amputations of pectoral fins were performed every two months. The bone elements of the shoulder girdle and pectoral fins were measured and compared between terrestrialized organisms and controls. Results: Terrestrialization produces notable morphological alterations, including general reduced body growth and big eyes, serial amputations under this condition decreases the number of radial bones of pectoral fins. Conclusions: We propose allometry and heterochrony as reliable concepts to explain the modifications generated by terrestrialization. Also, we suggest that anatomical alterations in early tetrapod ancestors were an unavoidable consequence of the influence of environment on general metabolic processes associated with growth.

Keywords: Polypterus, fin, regeneration, allometry, heterochrony

\section{RESUMEN}

Antecedentes: Polypterus condensa características únicas que sorprendieron y confundieron a los naturalistas desde que Geoffroy St. Hilaire lo describiera y nombrara por primera vez en 1802. En esa época Polypterus fue visto como un anfibio primitivo o como el eslabón entre peces y anfibios. Los Polypteriformes tienen la capacidad de regenerar las aletas pectorales con la precisión que solo se ve en los anfibios urodelos y tienen la capacidad de poder respirar aire utilizando un par de pulmones. Objetivos: Fue evaluar cómo una condición forzada de vida en tierra pudiera afectar a los huesos de la cintura escapular y la regeneración de la aleta pectoral de Polypterus senegalus. Métodos: Los Polypterus fueron mantenidos en condiciones semi-terrestres durante nueve meses y se realizaron amputaciones iterativas de las aletas pectorales cada dos meses. Los elementos óseos de la cintura escapular y aletas pectorales fueron medidos y comparados entre organismos terrestrizados y controles. Resultados: La terrestrización produce alteraciones morfológicas notables, que incluyen reducción del tamaño corporal general y ojos mas grandes, las amputaciones seriales en esta condición provocaron que el número de huesos radiales de las aletas pectorales se redujera. Conclusiónes: Proponemos que los conceptos alometría y heterocronía pueden explicar las modificaciones generadas por la terrestrización. Así mismo, sugerimos que las alteraciones anatómicas en los ancestros de los tetrápodos fueron una consecuencia inevitable de la influencia del medio ambiente sobre los procesos metabólicos generales asociados con el crecimiento.

Palabras clave: Polypterus, aleta, regeneración, alometría, heterocronía 


\section{INTRODUCTION}

Polypterus share several morphological and developmental characteristics with lungfishes and extinct tetrapod-like fishes, but important exceptions are the absence of choana and robust pelvic bones. However, despite its frog-like development and larvae with external gills (Bartsch et al., 1997), now it is clear that Polypteriformes are the most basal Actinopterygian fishes (Noack et al., 1996). Another important characteristic is that Polypterus have the capacity to breathe air by spiracle-mediated aspiration using ventrally paired lungs and, therefore, potentially could live for a long time in a semiterrestrial environment (Graham et al., 2014). Additionally, Polypterus has the ability to regenerate their lobed pectoral fins within 30 days post-amputation with remarkable accuracy (Cuervo et al., 2012), a characteristic shared with African lungfishes (Conant, 1973), living urodele amphibians, and some extinct amphibians (Fröbisch et al., 2015). Since endoskeleton regeneration has only been observed in living freshwater vertebrates (Fröbisch et al., 2015), it is tempting to suggest that this capacity developed in tetrapods that colonized rivers and lakes distant from brackish and seawater.

Polypterus normally make use of their pectoral lobed fins for braking, turning, moving forwards and backwards, or rising their anterior body when sitting at the bottom of a pond or river. Polypterus senegalus can take advantage of these abilities when forced to live on land (i.e., terrestrialization), such that the use of pectoral fins and their "walking" performance improves in the long term (Standen et al., 2014). Apparently, this experimental living condition promotes anatomical modifications in the pectoral girdle bones that have been related with anatomical changes seen in stem tetrapods (Standen et al., 2014). Nonetheless, any anatomical modification observed needs to consider alternative interpretations since it is unlikely that Polypterus are equivalent to the tetrapod ancestors that attempted life on land. For example, Eusthenopteron was a strictly aquatic fish with lobed fins with lepidotrichia and the pectoral girdle attached to the skull. On the other hand, Acanthostega limbs lack lepidotrichia and the pectoral girdle is detached from the skull. It is remarkable that the scapulocoracoid bone in these tetrapod-like fishes had a glenoid cavity where the humerus head articulates forming an anatomical assembly entirely different from that of Polypterus (Hall, 2006; Cuervo et al., 2012).

In the present work, we aimed to evaluate how "terrestrialization" could affect growth and pectoral fin regeneration. We show that terrestrialized Polypterus remained with a complexion and size similar to that of immature juvenile fishes with no clear external dimorphism of the anal fin, however, females developed mature gonads. Besides, terrestrialized Polypterus showed evident bigger and protruding eyes, but we did not observe significant alterations of pectoral girdle bones attributable to terrestrialization. Finally, the fin regeneration of fishes living on land occurred at a slower rate than of those living underwater resulting, through iterative amputation-regeneration cycles, in regenerates with a reduced number of radial bones.

\section{Materials and methods}

The rearing habitat were acrylic boxes $(40 \times 20 \mathrm{~cm})$ with perforated floor, covered with a layer of pebbles and Java moss, and placed inside a tank of 90 gallons maintained at $28^{\circ} \mathrm{C}$ with living aquatic plants and filtering system; the water level was minimal (a $2 \mathrm{~mm}$ layer) and sprayed from above to maintain a humid environment (Fig. 1A). Commercially obtained juvenile bichirs were used for the experiments. No more than five juvenile fishes were kept per box. The containers for control fishes were located in the same tank but $15 \mathrm{~cm}$ below the water level. Fishes were fed daily with commercial pelleted food ad libitum for 10 minutes. We noted that terrestrialized fishes eat as avidly as controls along the time of the experiments. After sixteen days of terrestrialization, both pectoral fins of one group of fishes were amputated at the base with a nail clipper as previously reported (Cuervo et al., 2012). Then iterative amputations were performed at two-month intervals in control and terrestrialized fishes when complete regeneration is completed in both groups. To stain the endoskeleton, regenerated fins were amputated, fixed and dehydrated overnight (ON) in 100\% ethanol, then incubated in acetone for $24 \mathrm{~h}$ and stained for $3 \mathrm{~h}$ at $37{ }^{\circ} \mathrm{C}+\mathrm{ON}$ at room temperature in alcian blue and alizarin red in $70 \%$ ethanol with $5 \%$ acetic acid. Finally, they were rinsed in tap water before clearing in $1 \% \mathrm{KOH}$ and $20 \%$ glycerol for $24 \mathrm{~h}$ and then cleared in $50 \%$ glycerol and finally stored in $80 \%$ glycerol. The same protocol was used for euthanized fishes to stain the pectoral girdle bones. We evaluated the size of pectoral girdle bones of eighteen juvenile Polypterus from another batch (size $6.2 \pm 0.2 \mathrm{~cm}$ ) raised in fully aquatic environment to compare with theterrestrialized. For this evaluation, we measured the longest and the broadest lines drawn on cleithrum, supracleithrum and clavicle bones (Fig. 3B, D). For X-ray images, the Xtreme Bruker equipment was used; for determinations, fishes were anesthetized by immersion in cold water containing a $0.1 \%$ tricaine solution. We declare that the experiments performed were approved by the Bioethics Committee of the Instituto de Biotecnología, Universidad Nacional Autónoma de México, and the criteria used are in accordance with regulations used by the Universidad Veracruzana (NOM-062-Z001999 "Especificaciones Técnicas para la Producción, Cuidado y Uso de los Animales de Laboratorio", Secretaría de Agricultura Ganadería Desarrollo Rural, Pesca y Alimentación).

\section{RESULTS}

\section{Differential growth after terrestrialization}

The start of the juvenile period in Polypterus senegalus is defined by the external color change (the grayling stage), which coincides with the beginning of air breathing through their lungs and external gill resorption (Bartsch et al., 1997). Thus, we performed the terrestrialization experiments with a batch of thirty uniform juvenile fishes shortly after the grayling stage $(4.8 \pm 0.3 \mathrm{~cm}$ long). At this stage fishes are immature and the gender is not recognizable. Eighteen fishes forced to live on land for nine months (Fig. 1A) showed a notorious overall size reduction (amputated and non-amputated fishes; see below) of about 39\% (Fig. $1 \mathrm{~A}$, inset graph) (mean $7.2+/-0.3 \mathrm{~cm}$ with a range between 6.8 and $7.8 \mathrm{~cm}$ ) when compared with water raised controls (mean 11.9+/-0.9 $\mathrm{cm}$ with a range between 10.4 and $12.7 \mathrm{~cm}$ ) (Fig. 1B), an outcome similar to that reported by Standen et al. (2014). The size of nine-months terrestrialized fishes was reached by controls within the first two months and terrestrialized fishes did not show significant growth from the seventh month onwards. Despite the smaller size of terrestrialized fishes, no evident skeletal abnormality was detected (Fig. 1C) and most internal organs appeared normal in comparison with water-raised fishes of similar size.

Externally, a differential growth effect by terrestrialization was evident in nine-months land-raised fishes. Control fishes raised in water 
showed clear external sexual dimorphism, evidenced by the shape of the anal fin, a characteristic of Polypteriformes (Holden, 1971). In contrast, no marked sexual difference was externally observed in terrestrialized fishes (Fig. 1D) but, internally, six out of eight females developed grown oocytes (Fig. 1E). Otoliths were extracted and compared but did not show a noticeable difference in size and form (Fig. 1F). However, all (18/18) terrestrialized fishes developed protruding eyes with a diameter $21.8 \pm 1.04 \%$ bigger and $16.4 \pm 1.29 \%$ wider pupils as compared with control fishes of the same size and complexion (i.e., juvenile fishes of another batch) (Fig. 1G).

\section{Fin regeneration in terrestrialized fishes}

It is known that highly regenerative species such as newts can regenerate normal limbs after repeated amputations although, occasiona-
Ily, some skeletal elements are missed (Spallanzani, 1768; Yun et al., 2015). Therefore, it is expected that Polypterus is able also to perform repeated fin regeneration cycles and, thus, this ability can be used as an approach to monitor the long-term growth effect due to terrestrialization. Thirteen fishes were amputated and five non-amputated land-raised fishes were used as controls. The fins of a group of eight fishes maintained in water were also amputated (water-raised control fishes). Serial amputations of these groups after complete regeneration were performed at intervals (i.e., at least 8 weeks after amputation) and the number of radial bones in both pectoral fins was evaluated. Regenerated fins were well-formed with complete propterygium and metapterygium bones and the metapterygial edge did not appear to be affected by accidental ground friction. Interestingly, the number of radial bones in regenerates of terrestrialized fishes was reduced:
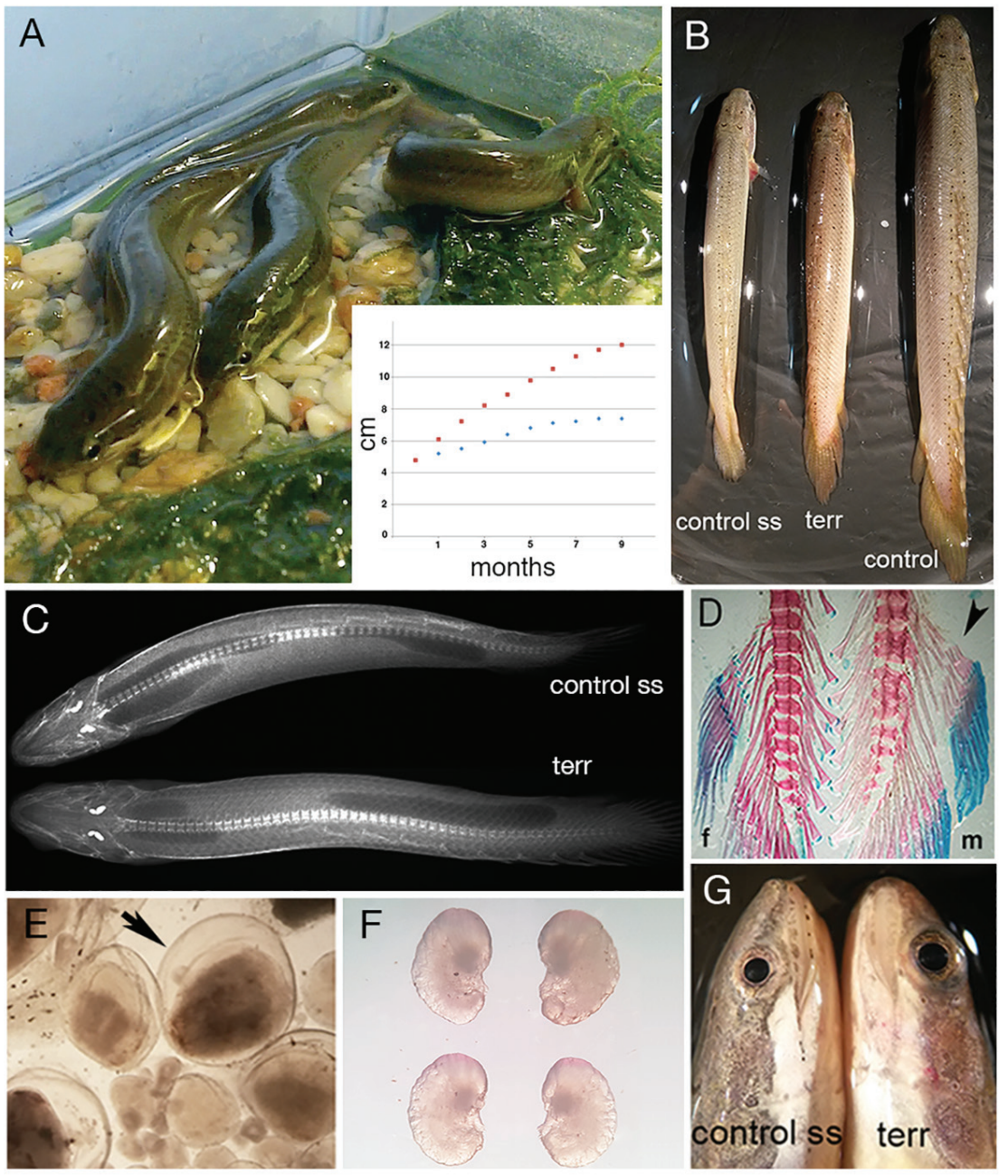

Figure 1. External growth abnormalities in terrestrialized Polypterus fishes. A, Terrestrialized Polypterus and diagram of growth progress. Red squares, control, blue squares, terrestrialized fishes. B, Comparative size of 9-months terrestrialized (terr) and two controls raised in water, one of the same age and batch (control) and one younger from another batch of the same size (control ss). C, Dorsal X-ray image of terrestrialized (lower) and control ss fishes (upper). No marked differences were observed. The internal dark zones evidenced well-developed lungs and the brighter spots in the head are the otholits. D, Anal fin show no marked external sexual dimorphism between female $(\mathrm{f})$ and male $(\mathrm{m})$ fishes. Arrowhead points the anterior radial bones characteristic of males. E, Grown and immature oocytes; arrow points the chorion of a developing oocyte. F, Pair of otholits of terrestrialized (lower) and control ss (upper) fishes. G, Eyes of terrestrialized (terr) fish compared with those of control of the same size (ss). Note the protruding and larger eye of a terrestrialized fish as compared with that of a control fish of the same size. 
the average number of radial bones per fin before amputation was 13.1 ( $n=30$ fins) and, after four consecutive amputations, this number in water-raised controls was $10.8 \pm 1.2$ radials ( $n=16$ fins), whereas that in regenerated fins of terrestrialized fishes was $7.8 \pm 2.3$ radials $(\mathrm{n}=26$ fins) (Fig. 2A). The reduction in the number of radials was gradual according to the number of amputations (Fig. 2B). The reduction in the number of radials was possibly due to a growth adaptation under land-living conditions. In agreement with a growth effect by this forced living condition, a marked extension of the time required for pectoral fin regeneration was observed. For example, in the last round of amputations, we observed that at the ninth day post-amputation all control regenerating fins were in the fin fold stage of regeneration. Whereas terrestrialized fins were at the stage at which the blastema is still forming (Fig. 2C), and complete regeneration and ossification of radials took around fifty days for terrestrialized fishes in comparison with the thirty days required for controls. Nonetheless, it should be noted that regenerated pectoral fins were reduced in size but this was not directly associated with the number of radials; for instance, fins with 6 radials were not half the size of fins with 12 radials (Fig. $2 A$ ). Therefore, independent of the reduced fin size, the loss of radials is likely originated from the slower growth rate under land living conditions at the early stages of regeneration, time at which bone elements are specified.

\section{Morphological variability of Polypterus girdle bones}

After eleven months of terrestrialization, a group of five amputated and five control fishes were euthanized and the morphology of cleithrum, supracleithrum, and clavicle (the pectoral girdle bones) was evaluated (Fig. 3A). Also, we evaluated the pectoral girdle bones of eighteen juvenile Polypterus from another batch (size $6.2 \pm 0.2 \mathrm{~cm}$ ), raised in a fully aquatic environment (Fig. 3B, D). No evident anatomical alterations were detected between groups (i.e., amputated vs. non-amputated, land-raised vs. water-raised; Fig. 3A). Instead, the simple evaluation approach used here was sufficient to note in some cases an evident morphological variability between left and right pectoral girdle bones of up to $15 \%$ in the broad lines of supracleithrum and posterior opercular chamber edge of cleithrum (Fig. 3C). Due to the intrinsic morphological variability, we could not associate the shape of girdle bones with the living conditions. In addition, the juvenile scapulacoracoid, the bone that connects the endoskeleton of the fin with the pectoral girdle, is the last bone to ossify in this assemblage and normally shows marked variability in the extent of ossification even within the same fish (Fig. 3E).
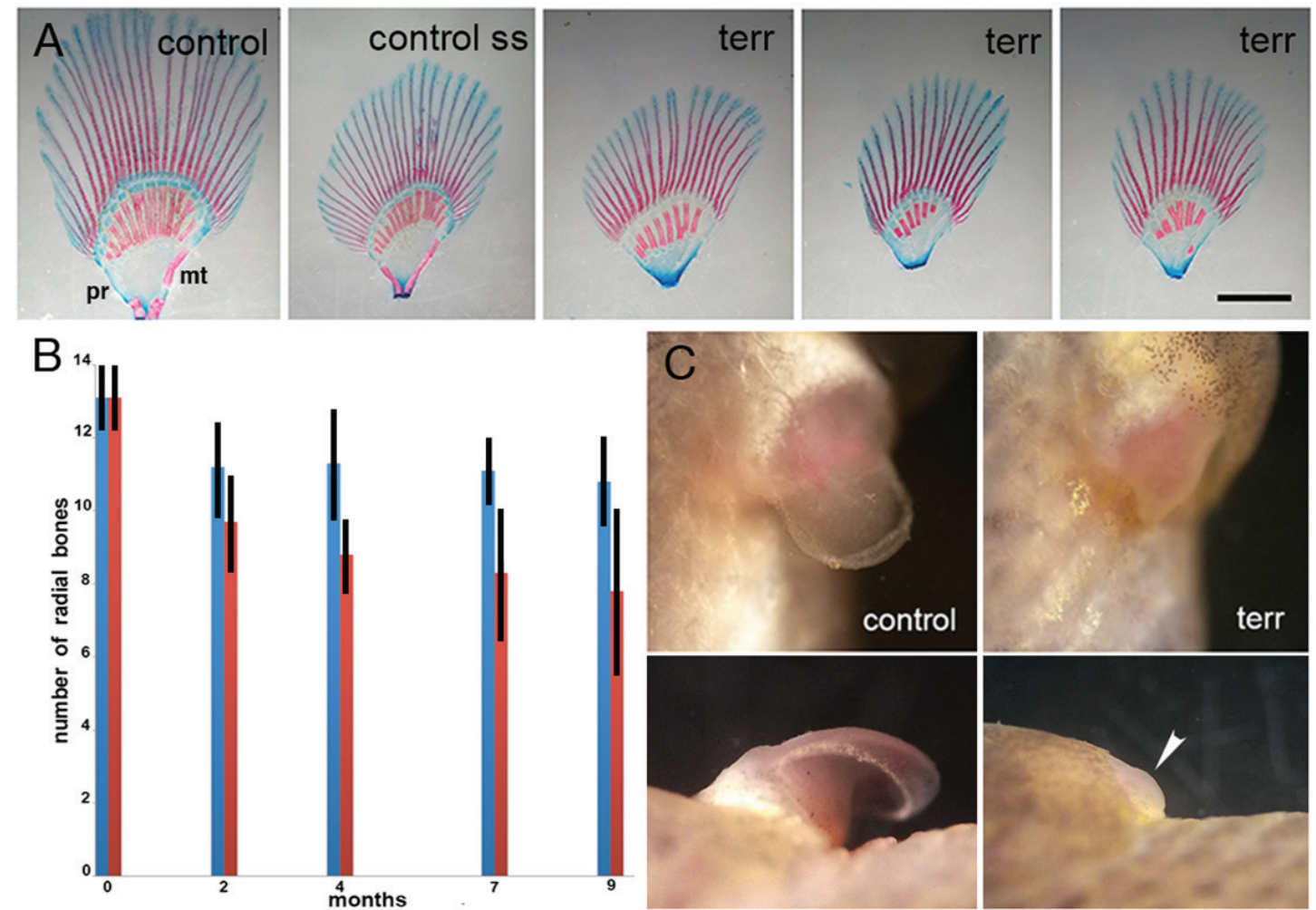

Figure 2. Fin regeneration in terrestrialized fishes. A. Alizarin red and alcian blue stained regenerated pectoral fins. Regenerated fins of water-raised fishes (control) were bigger than pectoral fins of terrestrialized fishes. Note the narrowed shape and the reduced number of radial bones in the fins of terrestrialized fishes, particularly evident when compared with a control of the same size (ss). Fins are placed in the same orientation for comparison. B, Number of radials formed in regenerated fins during the course of serial amputations along nine months. Amputations were done every 2 months; " 0 " represents the time of the first amputation. An initial reduction in the number of radials was observed in the first regenerate of either water or land-raised fishes, but during the succeeding regenerations events, only fins of the terrestrialized group showed a progressive reduction in the number of radials. C, Lateral (upper panels) and dorsal (lower panels) views of regenerating pectoral fins of water raised (control) and terrestrialized (terr) fishes at the fin fold stage of regeneration after nine days post amputation. Arrowhead point to the still forming blastema of a terrestrialized fish. mt, metapterygium. pr, propterygium. 


\section{DISCUSSION}

It is known that high oxygen levels in the atmosphere occurred during the transition from water to land. The fossil record support a direct relationship among the increase in atmospheric $0_{2}$ concentration, maximum body size and radiation of species (Dahl, 2010). However, a small body size might have been advantageous to support the bodyweight of early vertebrates living out of water. The parsimonious scenario would be that dwarf tetrapod ancestors might have had the advantage to make an excursion in land and colonize swamps but, once adapted to land, the atmospheric $\mathrm{O}_{2}$ concentration allowed them to rapidly gain size and weight. The small tetrapodomorph Kenichthys exemplified this possibility (Zhu \& Ahlberg, 2004). The advantage of a reduction in body size has also been documented for the evolution of birds (Lee, 2014). In this context, in addition to the influence of overall reduced growth for life on land, favorable conditions for morphological modifications might have also played a role in the rapid adaptation and evolution of early tetrapods. The reproducible phenotype observed in Polypterus living on land supports this proposal. The recent report showing that a conditional training in a semiterrestrial habitat improved the "walking" performance of the mostly water-living Polypterus fish experimentally shows the struggles that a fish on land might have suffered and that without doubt played a role in the selection for a terrestrial life (Standen et al., 2014).

The anatomical changes observed in most tetrapodomorph fossils indicate that mesomeres and lepidotrichia bones were first modified (Coates, 1994). A reduction in the number of radial bones and the eventual loss of the dermal skeleton that rim the ancestral fin-limb occurred previously to the detachment of the pectoral girdle from the skull. In concordance, modifications in the apical ectodermal ridge-apical fold transition by iterative apical fold removal links lepidotrichia reduction with endoskeleton expansion in developing pectoral fins of zebrafish (Yano et al., 2012). Later, scapulocoracoid growth occurred possibly as an essential event to support the upper body weight. Many authors agree that very few of the adaptations suffered by stem tetrapod are in fact adaptations for life on land; rather, most of them are aquatic specializations that just fortuitously allowed terrestrial life (Triques \& Christoffersen, 2009). Following this view, the term exaptation has been proposed to define a character previously shaped by natural selection for a particular function coopted for a new function (Gould \& Vrba, 1982).

Based in small changes in the shape of pectoral girdle bones determined in terrestrialized Polypterus, the view described above was recently challenged, and developmental plasticity (polyphenism) was
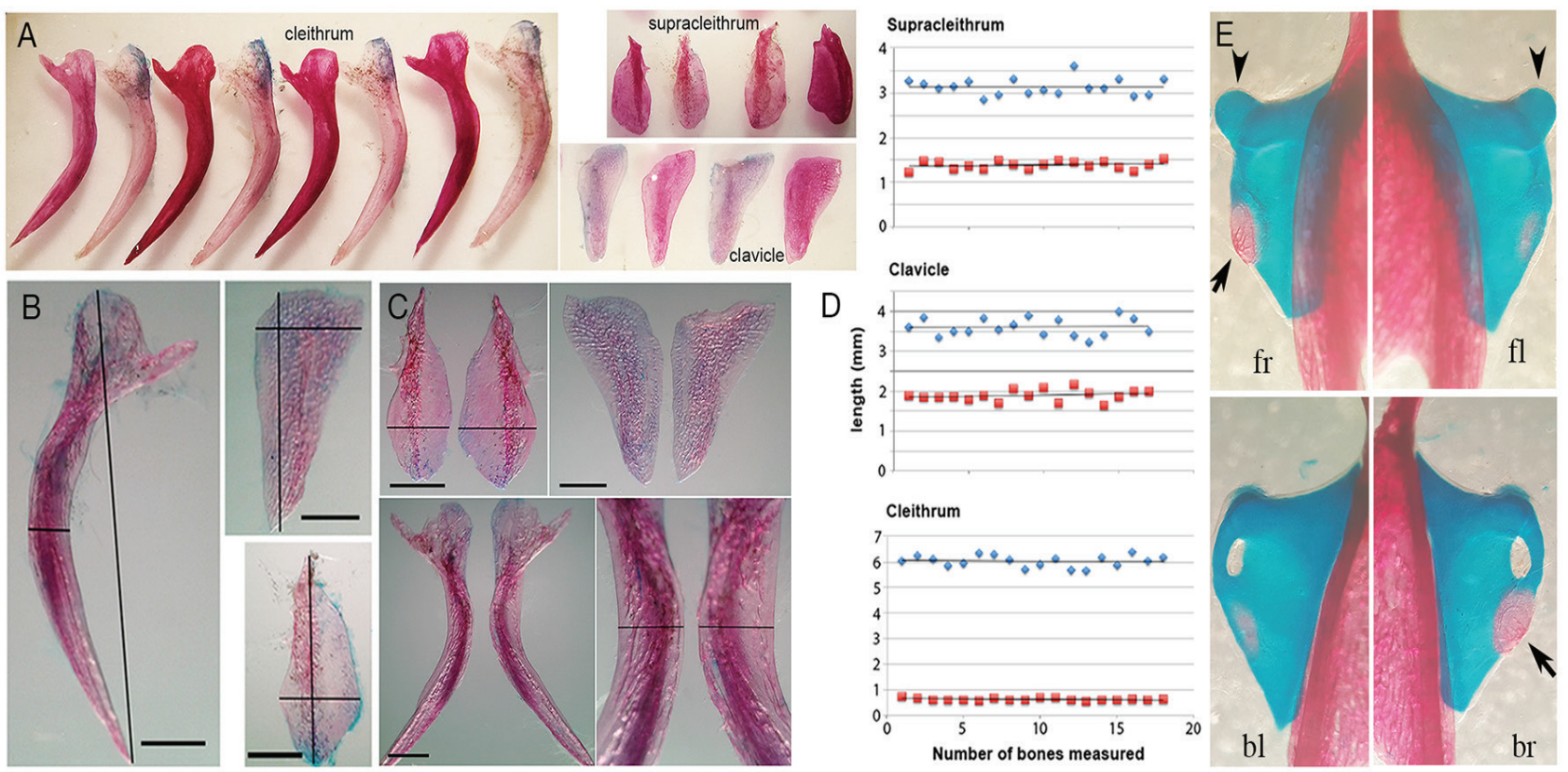

Figure 3. Comparative anatomy of pectoral girdle bones of water- and land-raised fishes. A, A comparison between cleithrum, clavicle or supracleithrum bones of non-amputated terrestrialized fishes (lighter alizarine red staining) and of controls of the same size (stronger alizarine red staining). B, Measurements done on pectoral girdle bones. Red and blue lines drawn are the maximum width and high, respectively, found in each sample. For cleithrum red line measure the medial zone of the posterior opercular chamber edge (scale bar, 1mm). C, A comparison between left and right pectoral girdle bones of the same fish. Evident differences in shape and size were observed for each bone element (scale bar, $1 \mathrm{~mm}$ ); in particular, note the significant difference in width of supracleithrum and at the middle opercular chamber edge of cleithrum. D, Estimation of girdle bone morphology variability. Morphology variability was estimated by measuring and comparing width (red squares) and high (blue rhombus) lines as indicated in B. E, Frontal (upper panels) and backward (lower panels) scapulocoracoid attached to cleithrum. Note the difference in ossification between right and left pectoral girdles of the same fish (arrow). The head bone where propterygium and metapterygium articulates is pointed with arrowhead. fr, frontal right; fl, frontal left; br, backward right; bl, backward left. 
proposed as a macroevolution mechanism that facilitated the origin of tetrapod characters that allowed the terrestrial life (Standen et al., 2014). Our observations show that outlines of bones that compose the pectoral girdle are intrinsically heterogeneous with a significant margin of variability even within the same fish (Fig. 3). The slight anatomical modifications reported attributable to developmental plasticity, as narrowed and $10.6 \%$ longer clavicles, reduced supracleithrum and posterior opercular chamber edge (Standen et al., 2014), fit within the margin of normal variability that we determined (Fig. 3C), and not necessarily arose as a consequence of the forced living conditions. Furthermore, a fundamental bone in tetrapod evolution, the scapulocoracoid (Fig. 3E, and 4), the bone that mediates the mechanical forces between the endoskeleton of the fin and pectoral girdle bones, was not considered in that work. In juvenile Polypterus, the scapulocoracoid is formed of cartilage and is the last bone ossify of the pectoral girdle assemble (Fig. $3 \mathrm{E})$. It is noteworthy that the scapulocoracoid bone in tetrapods and tetrapod-like fishes had a socket to articulate the humerus head (the glenoid cavity) (Hall, 2006). In contrast, the opposite appears to occur in Polypterus, that is, the propterygium and metapterygium bones articulate with a convex head bone that protrudes from the scapulocoracoid (Fig. 3E) (Cuervo et al., 2012). Therefore, training directed to optimize a particular biomechanical performance may be the result of the intrinsic and already existing physiological and morphological capabilities of Polypterus (Fig. 4) and not the expression of a polyphenism per se.

In contrast with girdle bones, we did observe the reduced size of pectoral fins after successive regeneration cycles in terrestrialized
Polypterus. In this context, it is interesting that the marked reduction in size observed in regenerates of axolotls after repeated limb amputations at the bud stage did not cause evident and reproducible morphological alterations but the reduction in the size of the complete limb (Yun et al., 2015). Heterochrony has been defined in terms of shifts in the onset or cessation of a specific developmental process (Klingenberg, 1998). The delay in the formation of the fin fold and the extended time to attain a complete regeneration and ossification of radials fit that definition. In a broad sense, as stated by Gould (2000) heterochrony refers to a change in the relative timing of developmental events resulting in changes in size and shape. For this reason, allometric growth, causing the uneven scaling of body parts in relation to the whole body, is a process which origin could be related to heterochrony. Thus, the small fins regenerated as well as the big eyes, can fit the allometry definition.

We cannot discard that specific modifications such as big and protruding eyes and slender lobed fins with few radials might have resulted, by chance, in changes useful to colonize wetlands. Then, it is advisable to envision a complex experimental scenario combining terrestrialization with high oxygen levels, brackish water, high temperature, etc., in which Polypterus or other fishes used to study the swimming-to-walking transition as the catfish or lungfish (Johnels, 1957; King et al., 2011) are forced to live, in order to evaluate the anatomical modifications and behavioral changes induced by the environment and get insights about the events that occurred in the short period of time when tetrapods prevailed on land.
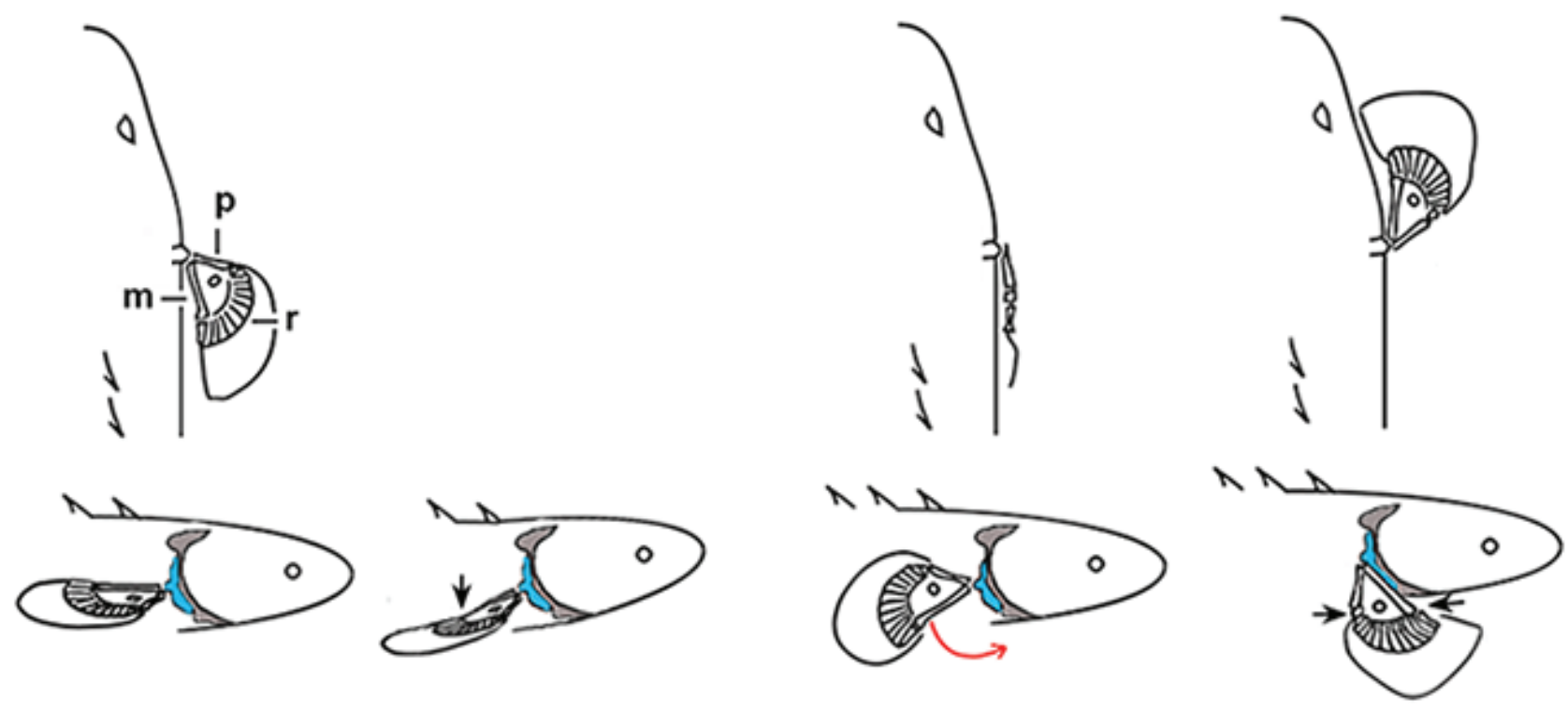

Figure 4. Schematized dorsal and lateral views of Polypterus. The location ofradials, propterygium and metapterygium bones attached to scapulocoracoid (blue) in relation to the corresponding pectoral girdle bones (gray) are shown. In the tetrapod-like position, the pectoral fins have a wide range of movements, including forwarding movements (red arrow) and a slight flexion and extension at the "wrist" (black arrows), as occurs in tetrapods. The fin ventral side is used to rest or to move on the ground.p, propterygium; m, metapterygium; r, radials. 


\section{ACKNOWLEDGMENTS}

This work was supported by grants 151757 from Consejo Nacional de Ciencia y Tecnología (CONACyT) and IN209813 from PAPIIT-UNAM.

\section{REFERENCES}

Bartsch, P., S. Gemballa \& T. PIOtrowski. 1997. The embryonic and larval development of Polypterus senegalus Cuvier, 1829: its staging with reference to external and skeletal features, behaviour and locomotory habits. Acta Zoologica 78: 309-328. D0I: 10.1111/j.14636395.1997.tb01014.x

COATES, M. I. 1994. The origin of vertebrate limbs. Development Supplement: 169-180.

Coates, M. I., J. E. Jeffery \& M. Rut. 2002. Fins to limbs: what the fossils say. Evolution and Development 4: 390-401. D0I: 10.1073/ pnas.1006619109

Conant, E. B. 1973. Regeneration in the African lungfish, Protopterus. 3. Regeneration during fasting and estivation. Biological Bulletin 144: 248-261. DOI: $10.2307 / 1540006$

Cuervo, R., R. Hernández-Martínez, J. Chimal-Monroy, H. Merchant-Larios \& L. CovarRuBiAs. 2012. Full regeneration of the tribasal Polypterus fin. Proceedings of the National Academy of Sciences 109: 3838-3843. DOI: 10.1073/pnas.1006619109

Dahl, T. W., E. U. Hammarlund, A. D. Anbar, D. P. G. Bond, B. C. Gill, G. W. Gordon, A. H. Knoll, A. T. Nielsen, N. H. Schovsbo \& D. E. Canfield. 2010. Devonian rise in atmospheric oxygen correlated to the radiations of terrestrial plants and large predatory fish. Proceedings of the National Academy of Sciences 107: 17911-17915. D0I: 10.1073/ pnas. 1011287107

Fröbisch, N. B., C. Bickelmann, J. C. Olori \& F. Witzmann. 2015. Deep-time evolution of regeneration and preaxial polarity in tetrapod limb development. Nature 527: 231-234. D0I: 10.1038/nature15397

Gould, S. J. \& E. S. VRBA. 1982. Exaptation a missing term in the science of form. Paleobiology 8: 4-15. DOI: 10.1017/S0094837300004310

GouLD, S. J. 2000. Of coiled oysters and big brains: how to rescue the terminology of heterochrony, now gone astray. Evolution and Development 2: 241:248. D0I: 0.1046/j.1525-142x.2000.00067.x

Graham, J. B., N. C. Wegner, L. A. Miller, C. J. Jew, N. C. Lal, R. M. Berquist, L. R. Frank \& J. A. Long. 2014. Spiracular air breathing in polypterid fishes and its implications for aerial respiration in stem tetrapods. Nature Communications 5: 3022. D0I: 10.1038/ncomms4022
HALL, B. K. 2006. Fins into Limbs: Evolution, Development, and Transformation. University of Chicago Press. D0I: 10.1007/s10914-0079049-3

HoLdEN, M. J. 1971. Significance of sexual dimorphism of the anal fin of Polypteridae. Nature 232: 135-136. D0I: 10.1038/232135b0

Johnels, A. G. 1957. The mode of terrestrial locomotion in Clarias. Oikos 8: 122-129. D0I: $10.2307 / 3564996$

King, H. M., N. H. Shubin,M. I. Coates \& M. E. Hale. 2011. Behavioral evidence for the evolution of walking and bounding before terrestriality in sarcopterygian fishes. Proceedings of the National Academy of Sciences 108: 21146-21151. DOI: 10.1073/pnas.1118669109

KLINGENBERG, C. P. 1998. Heterochrony and allometry: the analysis of evolutionary change in ontogeny. Biological Reviews of the Cambridge Philosophical Society 73: 79-123.

Lee, M. S. Y., A. Cau, D. Naish \& G. J. Dyke. 2014. Dinosaur evolution. Sustained miniaturization and anatomical innovation in the dinosaurian ancestors of birds. Science 345: 562-566. D0I: 10.1126/ science. 1252243

Noack, K., R. Zardoya \& A. Meyer. 1996. The complete mitochondrial DNA sequence of the bichir (Polypterus ornatipinnis), a basal ray-finned fish: ancient establishment of the consensus vertebrate gene order. Genetics 144: 1165-1180.

SpallanzanI, L. 1768. Prodromo di un'opera da imprimersi sopra le riproduzioni animali. In Modena: Nella Stamperia di Giovanni Montanari. $106 \mathrm{p}$.

Standen, E. M., T. Y. Du \& H. C. E. Larsson. 2014. Developmental plasticity and the origin of tetrapods. Nature 513: 54-58. D0I: 10.1038/ nature13708

Triques, M. L. \& M. L. Christoffersen. 2009. Exaptations in the conquest of land by Tetrapoda. Gaia Scientia 3: 69-74. D0I: 10.21707/gs. v3i2.3984

Yano, T., G. Abe, H. Yokoyama, K. Kawakami \& K. Tamura. 2012. Mechanism of pectoral fin outgrowth in zebrafish development. Development 139: 2916-2925. DOI: 0.1242/dev.075572

Yun, M. H., H. DavaAil \& J. P. Brockes. 2015. Recurrent turnover of senescent cells during regeneration of a complex structure. eLife 4: e05505. DOI: 10.7554/eLife.05505.015

Zнu, M., \& Р. Е. АнцвеRg. 2004. The origin of the internal nostril of tetrapods. Nature 432: 94-97. D0I: 10.1038/nature02843 